\title{
Novos Cenários para Velhos Trajetos: O Nordestino sofre Discriminação Salarial na Região Sudeste do Brasil?
}

\author{
Rebeca Maria Nepomuceno Lima ${ }^{1}$ | Evandro Camargos Teixeira ${ }^{2}$ \\ ${ }^{1}$ Departamento de Economia, Universidade Federal de Viçosa. E-mail: rebeca.econ@gmail.com \\ 2 Departamento de Economia, Universidade Federal de Viçosa. E-mail: evandro.teixeira@ufv.br
}

\begin{abstract}
RESUMO
A desigualdade regional incentivou a migração interna brasileira ao longo do século XX. Apesar do avanço nos fluxos migratórios de retorno a partir da década de 1980, a região Nordeste continua a ser a principal emissora e o Sudeste a principal região receptora. O presente estudo tem como objetivo central verificar se o migrante nordestino é sujeito a discriminação no mercado de trabalho da região Sudeste em consequência da sua região de nascimento, quando comparado aos demais migrantes. A análise foi realizada para os migrantes homens, através dos dados da Pesquisa Nacional por Amostra de Domicílios (PNAD) de 2015. De maneira geral, por meio da decomposição de Oaxaca-Blinder com correção de Heckman, evidencia-se o efeito discriminatório relacionado à região de nascimento ao comparar os migrantes nordestinos não brancos com aqueles oriundos da região Norte. Nas demais comparações realizadas entre migrantes, verificouse que a diferença salarial entre nordestinos e aqueles nascidos em outras regiões, brancos e não brancos, é explicada pela discrepância educacional.
\end{abstract}

\section{PALAVRAS-CHAVE}

Diferenciação salarial, Migração, Decomposição de Oaxaca-Blinder

New Scenarios for Old Path: Does the Northeast Migrant Suffer Wage Discrimination in the Brazilian Southeast Region?

\begin{abstract}
Regional inequality encouraged Brazilian internal migration throughout the 20th century. Despite the advance in migratory return flows since the 1980s, the Northeast continues to be the main source and the Southeast the main recipient region. The present study has as main objective to verify if the northeastern migrant is subject to discrimination in the labor market in the Southeast region as a result of his region of birth, when compared to the other migrants. The analysis was carried out for male migrants, using data from the 2015 National Household Sample Survey (PNAD). In general, through the decomposition of Oaxaca-Blinder with Heckman's correction, the discriminatory effect related to the region of birth when comparing non-white northeastern migrants with those from the northern region. In the other comparisons made between migrants, it was found that the wage difference between northeastern and those born in other regions, white and non-white, is explained by the educational discrepancy.
\end{abstract}

\section{KEYWORDS}

Wage differentials, Migration, Oaxaca-Blinder decomposition

\section{CLASSIFICAÇÃO JEL}

J31, J71, R23 


\section{Introdução}

A desigualdade econômica regional brasileira, que perpassa a agenda política há muitas décadas, tem como uma de suas consequências a dinâmica das migrações internas. O processo de industrialização concentrado na região Sudeste fez com que essa região, principalmente no caso do estado de São Paulo, atraísse um elevado fluxo migratório oriundo das demais regiões do país. Adicionalmente, as regiões Norte e Centro-Oeste também atraíram um contingente considerável de migrantes em função da expansão de suas fronteiras agrícolas, de forma que as regiões Sul e Nordeste do Brasil foram caracterizadas como regiões expulsórias de mão de obra (Maciel e Cunha, 2013).

No entanto, a partir da década de 1980, os fluxos migratórios se reverteram, efetivando um novo cenário impulsionado por migrações de retorno, as quais foram propiciadas por diversos fatores, dentre eles a crise econômica da década de 1980, os movimentos de fronteiras agrícolas, o aumento dos gastos públicos, a "guerra fiscal” ocorrida em alguns estados e a desconcentração produtiva (Martine, 1980; Cano, 1997).

Porém, ainda que posteriormente, entre os anos de 2000 e 2010, tenha ocorrido redução no número de deslocamentos em direção ao Sudeste, a região continua se destacando como a mais economicamente dinâmica do país e assim a mais atrativa para os migrantes inter-regionais (Baeninger, 2012).

Diante da dinâmica migratória apresentada, a literatura elenca diversas razões que justificam a decisão de deslocamento geográfico, inclusive que respaldam as mudanças recentes no fluxo migratório do país. Para fins de análise, o presente estudo terá como ênfase os incentivos econômicos que determinaram os referidos fluxos migratórios.

Nesse sentido, se por um lado existe a expectativa de que o migrante aumente seus ganhos com o deslocamento, por outro lado há evidências teóricas e empíricas de que o mercado de trabalho está sujeito a um comportamento discriminatório, o que poderia impactar nos ganhos relativos a partir da migração. Nesse sentido, a existência de discriminação econômica no mercado de trabalho ocorre quando um grupo de indivíduos recebe salários distintos ou é sujeito a um tratamento diferenciado em função de características específicas que não impactam em sua produtividade, tais como raça, gênero, cor, idioma, condição econômica, aparência física ou etnia (Beller et al., 1994; Becker, 1957; Darity, 1998).

Nesse contexto, a discriminação no mercado de trabalho pode ser classificada em quatro tipos (Loureiro, 2003): (1) discriminação salarial, quando um grupo de trabalhadores recebe salários menores do que outro grupo, apesar de realizarem o mesmo trabalho; (2) discriminação de emprego, que ocorre quando um grupo fica em desvantagem no que se refere à menor oferta de vagas, de forma que tal grupo é mais 
propenso ao desemprego; (3) discriminação de trabalho, que corresponde à restrição ou proibição arbitrária para que um grupo específico exerça certa atividade; (4) discriminação de oportunidades, que decorre da distribuição desigual de incentivos ao aumento do capital humano, como o fornecimento de treinamento para um determinado grupo em detrimento aos demais. Para fins de análise, o presente estudo tem como ênfase a análise do primeiro tipo, discriminação salarial, em decorrência de o indivíduo ter nascido na região Nordeste do Brasil.

Assim, no que tange especificamente à discriminação salarial, é ampla a literatura que a analisa no contexto brasileiro. Parte desses trabalhos, como os de Fernandes (2015); Souza et al. (2015), realizou análises com base no gênero ou na cor do indivíduo e apresentou resultados que corroboram a ideia de que indivíduos negros e do sexo feminino estão sujeitos à discriminação salarial. Além da avaliação desses fatores, outros estudos avaliaram a discriminação entre os indivíduos do mesmo gênero e raça, por meio de algumas outras características, tais como aparência física, peso e local de residência. Quanto ao último aspecto, Sachsida et al. (2004); Bóo e Trako (2009) apontam a existência de punição salarial para os trabalhadores que residem em regiões mais pobres se comparados àqueles que moram em regiões mais desenvolvidas.

Além do local de residência, não são incomuns estudos que retratam a diferença salarial do migrante interno no Brasil. Elenca-se que os migrantes possuem características endógenas, que em conjunto a um ambiente econômico mais propício, fomentam o aumento salarial relativo (Rodrigues et al., 2016; Aguiar et al., 2018). No entanto, a condição de migrante pode desencadear um efeito desfavorável, seja por adaptação social ou porque no local de destino suas características podem ter valores distintos das do seu local de origem (Batista e Cacciamali, 2009).

Em suma, o impacto econômico da migração é volátil ao tempo e à localidade, podendo ser benéfico ou prejudicial (Yap, 1976). No caso da região Sudeste, alguns estudos apontam que a diferença salarial por sexo é menor entre a população migrante (Batista e Cacciamali, 2009), no entanto a discriminação em função da raça é relativamente maior se comparada a outras regiões (Campante et al., 2004; Cambota e Marinho, 2007).

Levando-se em consideração que o Brasil é um país caracterizado por discrepâncias regionais, o que propicia diferenciação cultural, social e econômica, o processo adaptativo pode se diferenciar entre as regiões, tanto do ponto de vista da população migrante quanto da perspectiva da população receptora. Dessa forma, é relevante analisar se a região de nascimento do migrante desencadeia diferenciação salarial, seja de forma positiva ou negativa, em decorrência de fatores discriminatórios ou não em relação a ela. Nesse raciocínio, é totalmente plausivel a hipótese de que o migrante oriundo de uma região mais pobre esteja sujeito a efeitos discriminatórios no mercado de trabalho em uma região economicamente mais desenvolvida. 
Considerando-se o histórico do fluxo migratório interno no Brasil, no qual a região Nordeste é a principal emissora e o Sudeste o principal receptor, o presente estudo busca verificar se há diferenciação salarial para os migrantes nordestinos quando comparados aos migrantes das demais regiões. Além disso, analisa-se se essa diferenciação está relacionada com sua região de origem, sendo reflexo de fatores não produtivos. Com esse objetivo, a pesquisa contribui para a literatura ao aprofundar a abordagem da discriminação salarial para além do gênero e da raça, abordando-a do ponto de vista da dinâmica migratória no Brasil, representada pelos indivíduos nascidos na região Nordeste e residentes no Sudeste.

Cabe ainda salientar que, considerando os estudos já realizados, a definição de migração pode variar de acordo com a modalidade considerada. Essa questão é sintetizada por Cunha (2005) que, ao analisar a modalidade interestadual, afirma que o migrante pode ser definido a partir de três critérios conceitualmente distintos. $\mathrm{O}$ critério de "residência anterior" ou última etapa se restringe à análise do migrante a partir da última informação. Já o critério de "lugar de nascimento" considera os migrantes acumulados, que já migraram alguma vez na vida, porém não consideram o período de migração. Por fim, o critério "residência nos últimos cinco anos" ou data fixa permite combinar o período do deslocamento com o espaço geográfico.

Levando-se em consideração o objetivo do estudo, a definição de migrante adotada considerou a região de nascimento. Adicionalmente, uma vez que a melhoria nas condições socioeconômicas do migrante está diretamente relacionada com o tempo de residência no local de destino (Martine, 1980), essa característica foi adicionada ao critério de definição do migrante. Assim, consideraram-se como migrantes somente aqueles que se deslocaram, no mínimo, nos últimos cinco anos. Ademais, optou-se por restringir a análise aos migrantes do sexo masculino, pois esses, em sua maioria, são consideradas pessoas de referência nos domicílios e, portanto, primordiais no processo de decisão a respeito da migração, cujas motivações são essencialmente econômicas.

Para atingir o objetivo da pesquisa, o trabalho está dividido em cinco seções, a contar desta introdução. Na segunda seção, apresenta-se o referencial teórico que versa sobre a economia da discriminação e a revisão de literatura, a qual inclui estudos sobre a diferenciação salarial dos migrantes. Na terceira seção, são discutidas a estratégia de identificação e a metodologia utilizada. Por fim, na quarta seção, os resultados são apresentados, seguidos pelas considerações finais.

\section{A Economia da discriminação e da migração: uma breve revisão}

Os estudiosos da Economia da discriminação apontam a existência de dois grupos de modelos teóricos. Segundo Loureiro (2003), esses são divididos em modelos de discriminação por preferência e modelos de discriminação estatística. A primeira 
abordagem retrata o comportamento do indivíduo que tem preferência por discriminar. Conforme Becker (1957), as preferências do discriminador poderiam ser diferenciadas entre a utilidade do empregador, do empregado e do consumidor; e o ato da discriminação seria consequência direta da maximização das utilidades de cada agente.

Já os modelos do segundo tipo, discriminação estatística, partem do princípio de que o empregador ou credor não possui informações completas sobre os indivíduos. Dessa forma, o indivíduo pondera características dos grupos que sofrem discriminação para reduzir o valor do crédito ou salário. Na visão de Phelps (1972), a discriminação é em sua maior parte explicada pela crença dos empregadores de que certo grupo possui produtividade média menor do que o outro. Por sua vez, Arrow (1973) parte do pressuposto de que o trabalhador precisa receber um investimento para auferir um emprego. Nesse caso, se o empregado é julgado de forma preconceituosa, o investimento não é recebido e, portanto, não é observado.

Nesse aspecto, Yinger (1998) abordou a questão da discriminação no mercado consumidor norte-americano, especialmente no mercado imobiliário e no comércio de automóveis, concluindo que a barreira discriminatória em relação ao consumo não diminuiu ao longo das duas décadas precedentes. Ademais, para o autor, as evidências apontam que os estereótipos, os preconceitos e as disparidades decorrentes da discriminação passada ou histórica ainda incentivam os agentes econômicos a adotarem um comportamento discriminatório no tempo presente, como no caso dos afrodescendentes e hispânicos em território americano.

Com relação ao mercado de trabalho brasileiro, estudos empíricos também evidenciaram características contundentes de diferenciação salarial. Há existência de diferenciação salarial decorrente da discriminação devido à raça do trabalhador (Arcand e D'hombres, 2004), mas gênero e cor, em conjunto, podem potencializar as diferenças salariais no país, sendo majoritariamente desfavoráveis para mulheres e não brancos, persistentes até nas décadas mais recentes (Souza et al., 2015; Fernandes, 2015; Carvalho et al., 2006).

Em vista disso, a existência da discriminação é um tema relevante a ser considerado nos estudos que analisam o mercado de trabalho, uma vez que as perspectivas de trabalho têm implicações importantes para os indivíduos e para a situação econômica dos locais nos quais eles se inserem, de modo que elas podem impactar na decisão pela migração.

A respeito dessa temática, a literatura econômica aponta vários fatores que justificam a migração. Sob a ótica da teoria microeconômica neoclássica, a decisão de migrar é tomada pelo indivíduo racional a partir da análise de custo benefício de um retorno futuro. Já para os "novos economistas da migração do trabalho", a decisão está atrelada ao conjunto de pessoas proximamente ligadas e não por um indivíduo isolado (Massey et al., 1993). Por sua vez, na visão de Becker (1993), há uma correlação inversa entre educação e desemprego, sendo que a opção pela migração estaria 
atrelada ao investimento desejado pelo indivíduo em capital humano.

Para Sahota (1968), o ganho salarial é a variável econômica mais importante na tomada de decisão em migrar. Ademais, o tempo de residência é positivamente correlacionado com o retorno salarial (Martine, 1980). Contudo, isso não significa que os salários dos migrantes convergem em direção aos dos nativos. Isso porque os imigrantes podem possuir informações assimétricas de como suas habilidades são reconhecidas nos locais de destino, de modo que o retorno real da migração pode diferir daquele esperado (Borjas, 1994). Nesse aspecto, sendo a discriminação um diferencial salarial não explicado por características produtivas, essa pode gerar efeitos nos ganhos relativos dos trabalhadores, bem como em eventuais quebras de expectativas, as quais, por conseguinte, podem desestimular o deslocamento geográfico da mão de obra ou incentivar as migrações de retorno.

Nesse sentido, a análise da discriminação decorrente da migração também é abordada na literatura internacional. Veit e Thijsen (2019), por exemplo, analisaram a relação entre o local de nascimento e a contratação no mercado de trabalho. Os autores avaliaram se os empregadores de cinco países europeus - Alemanha, Países Baixos, Noruega, Espanha e Reino Unido - diferenciariam os trabalhadores de acordo com sua origem étnica (oriundos da Europa, Oriente Médio ou África). Como conclusão, o estudo apontou que a probabilidade em receber ofertas de emprego é menor para os nascidos em grupos etnicamente distantes, porém esse efeito não é o mesmo para todos os países, e, em algum caso, como no Reino Unido, o efeito se mostrou reverso.

Todavia, além da discriminação no ato de contratação, essa também pode se manifestar em outros aspectos, dentre eles no retorno salarial. Alguns estudos buscaram avaliar o retorno financeiro dos migrantes internos brasileiros no mercado de trabalho. Yap (1976) concluiu que a migração rural-urbana, no período após a Segunda Guerra Mundial, ocasionou efeito positivo para o crescimento econômico do Brasil e para elevação da renda, no entanto o acesso aos serviços sociais urbanos por parte dos migrantes seria limitado.

Utilizando dados da PNAD 2009, Maciel e Cunha (2013) destacaram que os migrantes oriundos do Nordeste - sem considerar o tempo da migração - são negativamente selecionados, ganhando em média $7,3 \%$ a menos do que os nativos na região Sudeste.

Com base nos dados dos Censos Demográficos de 1991 e 2000, relativos à Região Metropolitana de Campinas, Branchi e Barretto (2010) estimaram uma regressão múltipla para avaliar a receptividade do mercado de trabalho da região ao migrante. Os autores concluíram que os indivíduos naturais dos municípios paulistas se deparam com melhores condições no mercado de trabalho do que aqueles provenientes de outros estados brasileiros.

Resultados semelhantes aos estudos anteriores foram encontrados por Loureiro (2003), que utilizou dados da PNAD 2015 para estimar a equação de rendimentos de Mincer (1958), com correção de Heckman (1979), para estabelecer se a região de 
origem do migrante se relaciona com sua condição no mercado de trabalho. A autora afirmou que majoritariamente os migrantes internos são positivamente relacionados, exceto os nordestinos, que obtiveram retorno salarial negativo tanto na região Sudeste quanto na região Centro-Oeste.

Em suma, os trabalhos empíricos indicam a existência de discriminação no mercado de trabalho brasileiro, bem como evidenciam a diferenciação salarial na região Sudeste. Contudo, a evolução do rendimento do migrante depende de como o mercado de trabalho no local de destino valoriza suas qualificações, o que pode ser distinto entre as diversas regiões do país.

\section{Estratégia de identificação e procedimentos econométri- $\cos$}

\subsection{Estratégia de identificação}

A mensuração de um possível efeito discriminatório no mercado de trabalho da região Sudeste, causado pelo local de origem do indivíduo, especificamente o Nordeste, seria idealmente avaliada se fosse possivel comparar a trajetória profissional de trabalhadores com características produtivas; físicas, dadas as evidências de discriminação por raça e gênero; e econômicas, dada a possibilidade de discriminação por características socioeconômicas semelhantes, distinguindo-os apenas pela região de nascimento.

Levando em consideração a inviabilidade da realização do experimento ideal, é importante fazer algumas considerações. Inicialmente, é importante destacar que as variáveis correspondentes à migração possuem características endógenas quando avaliadas sob a perspectiva do mercado de trabalho. Como já indicado na revisão de literatura, os migrantes internos brasileiros podem ter características próprias como determinação, ambição, entre outras - que afetam tanto sua propensão a migrar quanto a pretensão salarial (Rodrigues et al., 2016; Aguiar et al., 2018).

Não é errôneo supor que as características próprias dos migrantes podem ser distintas, especialmente quando eles são segregados pela região de nascimento. Isto é, o migrante nordestino pode ter atributos menos valorados no mercado de trabalho em relação ao migrante de outras regiões. Esses atributos não estão necessariamente vinculados apenas à localidade geográfica, mas também aos aspectos socioeconômicos dessa localidade. Partindo da teoria referente aos modelos de discriminação estatística, optou-se por considerar o migrante a partir da sua região de nascimento, pois o objetivo é verificar a hipótese de que o fato de o indivíduo possuir ascendência nordestina impactaria de forma negativa em sua valoração no mercado de trabalho. Por esse motivo, além da possibilidade de se trabalhar com um nível de agregação maior, optou-se por avaliar a migração do ponto de vista regional, em detrimento do municipal ou estadual. 
Finalmente, para evitar viés de seleção e tornar a interpretação causal válida, foi adotada a Suposição da Independência Condicional (CIA). De acordo com Angrist e Pischke (2008), com a realização do controle por variáveis observáveis, valendo-se da CIA, é possível comparar os dois grupos analisados na regressão e ainda evitar o viés de variável omitida.

Dessa forma, dois procedimentos foram adotados no presente estudo. O primeiro consiste em verificar se os indivíduos que se deslocam para a região Sudeste do Brasil são negativamente selecionados, ou seja, se os atributos dos migrantes são valorados negativamente no mercado de trabalho, de forma que eles já teriam tendência a receber salários mais baixos, independente da condição de migração. Essa avaliação é realizada a partir do modelo de seleção de Heckman (1979) em dois estágios.

O segundo procedimento refere-se à verificação da existência da discriminação salarial. Para tal, utiliza-se a decomposição de Oaxaca-Blinder para realizar uma comparação do migrante nordestino em pares: (a) Indivíduos nascidos nas regiões Nordeste e Norte; (b) Indivíduos nascidos nas regiões Nordeste e Sul; (c) Indivíduos nascidos nas regiões Nordeste e Centro-Oeste.

Objetivando-se a obtenção de grupos mais comparáveis, a amostra foi restrita aos indivíduos do sexo masculino, subdividindo-a em homens brancos (autodeclarados brancos na PNAD 2015) e não brancos (autodeclarados pardos, pretos, amarelos e indígenas). Ademais, como supracitado, optou-se por considerar como migrantes apenas os homens, nascidos em outras regiões, classificados na PNAD 2015 como residentes na região Sudeste há pelo menos cinco anos.

\subsection{Procedimentos econométricos}

A análise dos rendimentos foi estimada considerando-se características pessoais e do mercado de trabalho, a partir de dados da PNAD 2015, conforme a expressão abaixo, respaldada por Mincer (1958): ${ }^{1}$

$$
\begin{aligned}
& \ln \left(Y_{i}\right)=\beta_{0}+\beta_{1} \text { Sind }_{i}+\beta_{2} E s c 2_{i}+\beta_{3} E s c 3_{i}+\beta_{4} E s c 4_{i}+\beta_{5} \text { Casado }_{i}+\beta_{6} \text { Agrcola }_{i} \\
& +\beta_{7} \text { Indstria }_{i}+\beta_{8} \text { Construo }_{i}+\beta_{9} \text { Comerserv }_{i}+\beta_{10} \text { Urbano }_{i}+\beta_{11} \text { Non }_{n} \text { asc }_{i}+\beta_{12} \mathrm{Ne}_{n} \text { asc }_{i} \\
& +\beta_{13} N u_{n} a_{s c_{i}}+\beta_{14} \operatorname{Exp}_{i}+\beta_{15} \text { Exp }_{i}^{2}+\beta_{16} \text { Diretor }_{i}+\mu_{i}
\end{aligned}
$$

\footnotetext{
${ }^{1}$ Heckman (1979) aponta que a estimação pautada no trabalho de Mincer (1958) é enviesada, de forma que a estimação da taxa de retorno da educação seria superestimada. A literatura recente retrata que o nivel de escolaridade não é exógeno, como considerado na equação minceriana, sendo necessária a adoção de controles para ponderar o impacto da educação no salário (Barbosa Filho e Abreu Pessôa, 2010). Entretanto, o presente estudo tem como objetivo central verificar se há diferença salarial não explicada entre os migrantes relacionada com a origem de nascimento. Logo, a mensuração do impacto da educação atende a um objetivo secundário, referente apenas à sua significância na explicação das características observáveis dos indivíduos e não necessariamente à sua respectiva taxa de retorno para os rendimentos.
} 
considerando $\ln (Y)$ o logaritmo natural da renda do trabalho principal e $\mu$ o termo de erro. A descrição das demais variáveis é apresentada no Quadro 1.

A estimação da Equação (1) por MQO levaria a resultados inconsistentes, dada a existência de viés de seletividade decorrente do fato de apenas constarem observações de rendimentos para indivíduos após sua migração. O procedimento de Heckman (1979) em duas etapas foi utilizado para estimar a razão inversa de Mills e incluí-la na equação minceriana.

Tal procedimento consiste na estimação de duas equações, a de participação e a de rendimentos. Levando-se em consideração o problema de pesquisa, optou-se pela mensuração no primeiro estágio da probabilidade de o indivíduo migrar para a região Sudeste. Para evitar problemas de multicolinearidade, a equação de participação deve conter ao menos um regressor que não seja considerado na equação de resultado (Cameron e Trivedi, 2005). Isto é, ao menos uma variável de controle deve ser incluída no primeiro modelo associada à probabilidade de o indivíduo deslocar-se para a região Sudeste, mas não ao seu rendimento. As referidas variáveis foram descritas no Quadro 1.

Levando-se em consideração que pode existir relação endógena entre a probabilidade de o indivíduo migrar e o rendimento na região de destino, foi inserido o logaritmo natural do número de migrantes do estado de nascimento como instrumento na equação de seleção. A opção por incluir a referida variável se baseia em estudos os quais apontam que as taxas estaduais históricas podem ser utilizadas como instrumentos para as redes de migrantes. Essas proporcionam impacto positivo e significativo sobre os fluxos migratórios, mesmo após o controle de outras variáveis que afetam a migração (Ribeiro, 2017). A utilização do histórico das taxas estaduais está diretamente relacionada à ideia de que as "redes sociais" representam um sistema em que há um fluxo de troca, de pessoas e de informações, entre certas localidades, de modo que isso implicaria na origem e no desenvolvimento do próprio fluxo (Fazito, 2002; Fawcett, 1989). ${ }^{2}$

\footnotetext{
${ }^{2}$ Fazito (2002) afirma que, pela consolidação da abordagem sistêmica sobre a migração, a função das redes sociais se torna plausivel, considerando as teorias de correntes migratórias, as quais abordavam a presença de uma "força" que conectava regiões de origem e de destino por meio dos fluxos de migrantes.
} 
Quadro 1. Variáveis utilizadas no modelo econométrico

\begin{tabular}{|c|c|}
\hline Variável & Definição \\
\hline $\ln (\mathrm{Y})$ & Logaritmo do salário individual do trabalho principal. \\
\hline Sind & $\begin{array}{l}\text { Dummy, que atribui } 1 \text { para o indivíduo vinculado ao sindicato e } 0 \text { caso } \\
\text { contrário. }\end{array}$ \\
\hline $\operatorname{Esc1(b)}$ & $\begin{array}{l}\text { Dummy, que atribui } 1 \text { para o indivíduo que não completou ensino } \\
\text { fundamental e } 0 \text { caso contrário. }\end{array}$ \\
\hline Esc2 & $\begin{array}{l}\text { Dummy, que atribui } 1 \text { para o indivíduo com ensino fundamental } \\
\text { completo e } 0 \text { caso contrário. }\end{array}$ \\
\hline Esc3 & $\begin{array}{l}\text { Dummy, que atribui } 1 \text { para o indivíduo com ensino médio completo e } \\
\text { o caso contrário. }\end{array}$ \\
\hline Esc4 & $\begin{array}{l}\text { Dummy, que atribui } 1 \text { para o indivíduo com ensino superior completo e } \\
0 \text { caso contrário. }\end{array}$ \\
\hline Casado & Dummy, que atribui 1 para o indivíduo casado e 0 caso contrário. \\
\hline Agrícola & $\begin{array}{l}\text { Dummy, que atribui } 1 \text { para o trabalhador alocado no setor agrícola e } \\
0 \text { caso contrário. }\end{array}$ \\
\hline Indústria & $\begin{array}{l}\text { Dummy, que atribui } 1 \text { para trabalhador alocado no setor industrial e } \\
0 \text { caso contrário }\end{array}$ \\
\hline Construção & $\begin{array}{l}\text { Dummy, que atribui } 1 \text { para o trabalhador alocado no setor de construção e } \\
0 \text { caso contrário. }\end{array}$ \\
\hline Comerserv & $\begin{array}{l}\text { Dummy, que atribui } 1 \text { para o trabalhador alocado no setor de comércio ou } \\
\text { serviços e } 0 \text { caso contrário. }\end{array}$ \\
\hline Outros(b) & $\begin{array}{l}\text { Dummy, que atribui } 1 \text { para o trabalhador alocado em outros setores fora os } \\
\text { anteriores e } 0 \text { caso contrário. }\end{array}$ \\
\hline Urbano & $\begin{array}{l}\text { Dummy, que atribui } 1 \text { para o indivíduo que reside em zona urbana e } 0 \text { caso } \\
\text { contrário. }\end{array}$ \\
\hline No_nasc & Dummy, que atribui 1 para quem nasceu na região Norte e 0 caso contrário. \\
\hline Ne_nasc & $\begin{array}{l}\text { Dummy, que atribui } 1 \text { para quem nasceu na região Nordeste e } 0 \text { caso } \\
\text { contrário. }\end{array}$ \\
\hline Su_nasc & Dummy, que atribui 1 para quem nasceu na região Sul e 0 caso contrário. \\
\hline Co_nasc (b) & $\begin{array}{l}\text { Dummy, que atribui } 1 \text { para quem nasceu na região Centro-Oeste e } 0 \text { caso } \\
\text { contrário. }\end{array}$ \\
\hline $\operatorname{Exp}$ & Indica a experiência, calculada por: exper =idade-anos de estudo-6. \\
\hline $\operatorname{Exp}^{2}$ & Experiência ao quadrado. \\
\hline Idade & Idade do indivíduo em anos. \\
\hline Diretor & $\begin{array}{l}\text { Dummy, que atribui } 1 \text { caso o indivíduo assuma a posição de líder (diretor } \\
\text { ou gerente) e } 0 \text { caso contrário. }\end{array}$ \\
\hline Ref (h) & $\begin{array}{l}\text { Dummy, que atribui } 1 \text { se a pessoa é referência na família e } 0 \text { caso } \\
\text { contrário. }\end{array}$ \\
\hline Difeduca (h) & $\begin{array}{l}\text { Variável auferida pela diferença entre o nível médio de escolaridade dos indivíduos com } \\
18 \text { anos de idade entre os estados de origem e destino do migrante. }{ }^{(1)}\end{array}$ \\
\hline Pesdomic (h) & Número de residentes no domicílio. \\
\hline $\operatorname{lnmig}(\mathrm{h})$ & $\begin{array}{l}\text { Logaritmo natural do número de migrantes do estado de nascimento. } \\
\text { As informações dessa variável abrangem o período entre } 2000 \text { e } 2009 \text {, } \\
\text { tomando como base os valores expostos no trabalho de Ribeiro (2017). }\end{array}$ \\
\hline
\end{tabular}

Nota: ${ }^{(1)}$ Por considerar como migrante apenas os que residem no local de destino por pelo menos 5 anos. A variável em questão foi calculada a partir dos dados disponíveis pela Síntese de Indicadores Sociais (SIS- IBGE) para o ano de 2010. 
A inclusão dessa variável também possibilita a vantagem de acréscimo de um componente exógeno à decisão de migrar, que se diferencia entre os diferentes estados. Assim, a equação de seleção, estimada por meio do modelo Probit, é indicada por:

$$
\begin{aligned}
& \ln \left(Y_{i}^{*}\right)=\beta_{0}+\beta_{1} E s c 2_{i}+\beta_{2} E s c 3_{i}+\beta_{3} E s c 4_{i}+\beta_{4} \text { Casado }_{i}+\beta_{5} \text { Exp }_{i}^{2} \\
&+\beta_{6} \text { Idade }_{i}+\beta_{7} \text { Ref }_{i}+\beta_{8} \text { Difeduca }_{i}+\beta_{9} \text { Pesdomic }_{i}+\beta_{10} \text { lnmig }_{i}+\beta_{11} N o_{n} a s c_{i} \\
&+\beta_{12} N e_{n} a s c_{i}+\beta_{13} \text { Su }_{n} a s c_{i}+\varepsilon_{i}
\end{aligned}
$$

em que $y *$ assume valor igual a 1 se o indivíduo imigrou com destino à região Sudeste e 0 caso o indivíduo não tenha imigrado para a referida região. Se a razão inversa de Mills, obtida a partir da estimação da equação de seleção, for estatisticamente significativa, há indicativo de viés de seleção. Logo, essa deve ser incorporada na equação de determinação dos rendimentos, Equação (1).

Também é possível incorporar a razão inversa de Mills na decomposição de OaxacaBlinder, exposta por Oaxaca (1973) e Blinder (1973), cuja metodologia permite verificar o diferencial de rendimentos entre dois grupos. Conforme expresso na estratégia de identificação, neste estudo são utilizadas três composições, cada qual compara o migrante nordestino com aquele oriundo de outra região (Norte, Sul e Centro-Oeste). O diferencial de rendimentos pode ser obtido por:

$$
\begin{aligned}
D=\left[E\left(X_{\text {nordestino }}\right)-E\left(X_{\text {nao-nordestino }}\right)\right]^{\prime} \beta^{*} & +\left[E\left(X_{\text {nordestino }}\right)^{\prime}\left(\beta_{\text {nordestino }}-\beta^{*}\right)\right. \\
& \left.+E\left(X_{\text {nao-nordestino }}\right)^{\prime}\left(\beta_{\text {nao-nordestino }}-\beta^{*}\right)\right]
\end{aligned}
$$

Jann (2008) destaca que o primeiro termo da equação indica o diferencial de salário decorrente das características observáveis inseridas no modelo. Por sua vez, o segundo termo representa a parte inexplicada da diferença. Essa pode ser atribuída ao fator analisado, que no caso é o fato do migrante ter nascido na região nordestina.

\subsection{Dados}

Ao todo, foram consideradas 15.487 pessoas na amostra, sendo 6.058 autodeclaradas brancas e 9.429 autodeclaradas não brancas. Os dados utilizados no presente estudo foram retirados da PNAD do ano de 2015, pesquisa realizada pelo IBGE. Tal pesquisa é realizada anualmente e visa descrever a situação da população brasileira, referente a diversos aspectos, relacionados à renda, educação, trabalho, migração, dentre outros. A PNAD se caracteriza também por ser uma pesquisa com amostragem complexa, ou seja, estratificada e conglomerada. Anualmente, o IBGE seleciona domicílios aleatoriamente no país, cujas respostas são expandidas, via variáveis de 
pesos e estratos de modo a representarem toda a população brasileira.

Ao se utilizar a referida base de dados, é de suma importância que se considerem tais variáveis próprias do tipo de amostragem em estimações, tanto pontuais quanto intervalares; caso contrário, os resultados não são representativos para a população brasileira nem para a própria amostragem suposta simples. As variáveis de uso comum na estimação de amostragem complexa são aquelas relacionadas ao peso para o indivíduo selecionado para a pesquisa e ao estrato para a conglomeração dos indivíduos selecionados. A variável de peso é geralmente construída tendo em vista o inverso da probabilidade de seleção do indivíduo para a pesquisa, enquanto a variável de estrato se associa ao peso conferido às probabilidades de diferentes conglomerações serem selecionadas para a pesquisa.

\section{Resultados e discussão}

\subsection{Análise descritiva}

A análise prévia dados disponiveis é de suma importância para compreender os resultados paramétricos. Assim, as estatísticas descritivas da amostra utilizada são apresentadas na Tabela 1. É possivel perceber que os dois grupos são, em média similares no que se refere a atuação no setor formal, status marital e idade. No entanto, na média, o nível de escolaridade dos indivíduos não brancos é menor, sendo tal resultado recorrente na literatura (Campante et al., 2004; Gama e Machado, 2014).

Com relação ao deslocamento para a região Sudeste, a origem do indivíduo branco é majoritariamente as regiões Nordeste e Sul do país. Por outro lado, indivíduos migrantes não brancos são, em média, aqueles nascidos nas regiões Nordeste e Norte. Nesse caso, evidencia-se que a região Nordeste é a principal emissora em ambos os grupos, como ilustrado na Figura 1.

A Tabela 2 denota que a maioria dos migrantes analisados está inserida no mercado formal, especialmente os não caucasianos. Nota-se que o setor de Comércio e Serviços se destaca na absorção de trabalhadores migrantes. É importante também evidenciar que a maioria dos migrantes assume postos de trabalho formais na região Sudeste. No caso específico dos migrantes brancos nordestinos, $58 \%$ atuam em vínculos formais. Por sua vez, no caso dos não brancos, esse percentual é de 60\%.

Apesar do percentual relativamente elevado de formalização, a Figura 2 indica que em ambas as amostras o percentual de imigrantes nordestinos com nivel superior é relativamente menor. Essa relação pode corroborar o fato de que esses trabalhadores são majoritariamente alocados no segmento de Comércio, Serviços e de Construção - diferenciando-os dos imigrantes nascidos nas regiões Centro-Oeste e Sul, cuja segunda principal atividade de destino é a Indústria. 
Tabela 1. Estatísticas descritivas dos indivíduos analisados, sexo masculino, incluídos migrantes e não migrantes da região Sudeste

\begin{tabular}{|c|c|c|c|c|}
\hline \multirow[b]{2}{*}{ Variável } & \multicolumn{2}{|c|}{$\begin{array}{c}\text { Brancos } \\
(6.058 \\
\text { observações) }\end{array}$} & \multicolumn{2}{|c|}{$\begin{array}{l}\text { Não Brancos } \\
\qquad(9.429 \\
\text { observações) }\end{array}$} \\
\hline & Média & $\begin{array}{l}\text { Desvio- } \\
\text { Padrão }\end{array}$ & Média & $\begin{array}{l}\text { Desvio- } \\
\text { Padrão }\end{array}$ \\
\hline Migrante & $21 \%$ & 0,410 & $21 \%$ & 0,407 \\
\hline Sindicato & $20 \%$ & 0,401 & $18 \%$ & 0,386 \\
\hline Esc 1 & $22 \%$ & 0,412 & $31 \%$ & 0,464 \\
\hline Esc2 & $23 \%$ & 0,423 & $28 \%$ & 0,447 \\
\hline Esc3 & $33 \%$ & 0,471 & $31 \%$ & 0,462 \\
\hline Esc4 & $22 \%$ & 0,414 & $10 \%$ & 0,301 \\
\hline Casado & $6 \%$ & 0,243 & $6 \%$ & 0,242 \\
\hline Diretor & $9 \%$ & 0,290 & $4 \%$ & 0,203 \\
\hline Idade & 43 & 12,996 & 41 & 12,672 \\
\hline No_nasc & $5 \%$ & 0,220 & $11 \%$ & 0,309 \\
\hline Ne_nasc & $32 \%$ & 0,316 & $52 \%$ & 0,500 \\
\hline Su_nasc & $26 \%$ & 0,264 & $8 \%$ & 0,274 \\
\hline Co_nasc & $7 \%$ & 0,258 & $8 \%$ & 0,272 \\
\hline
\end{tabular}

Fonte: Elaboração própria a partir da PNAD 2015.

Tabela 2. Alocação dos migrantes por ramo de atividade, 2015

\begin{tabular}{|c|c|c|c|c|c|c|c|c|}
\hline & \multicolumn{4}{|c|}{ Brancos } & \multicolumn{4}{|c|}{ Não Brancos } \\
\hline & Norte & Nordeste & $\begin{array}{l}\text { Centro- } \\
\text { Oeste }\end{array}$ & Sul & Norte & Nordeste & $\begin{array}{l}\text { Centro- } \\
\text { Oeste }\end{array}$ & Sul \\
\hline Agrícola & $3 \%$ & $4 \%$ & $6 \%$ & $7 \%$ & $6 \%$ & $6 \%$ & $15 \%$ & $16 \%$ \\
\hline Indústria & $7 \%$ & $15 \%$ & $20 \%$ & $18 \%$ & $13 \%$ & $14 \%$ & $20 \%$ & $22 \%$ \\
\hline Construção & $14 \%$ & $23 \%$ & $13 \%$ & $17 \%$ & $29 \%$ & $27 \%$ & $19 \%$ & $17 \%$ \\
\hline Comércio e Serviço & $62 \%$ & $45 \%$ & $52 \%$ & $43 \%$ & $26 \%$ & $41 \%$ & $37 \%$ & $39 \%$ \\
\hline Outros & $14 \%$ & $12 \%$ & $9 \%$ & $14 \%$ & $26 \%$ & $11 \%$ & $9 \%$ & $6 \%$ \\
\hline
\end{tabular}

Fonte: Elaboração própria a partir da PNAD 2015. 
Figura 1. Classificação dos migrantes por local de origem, 2015

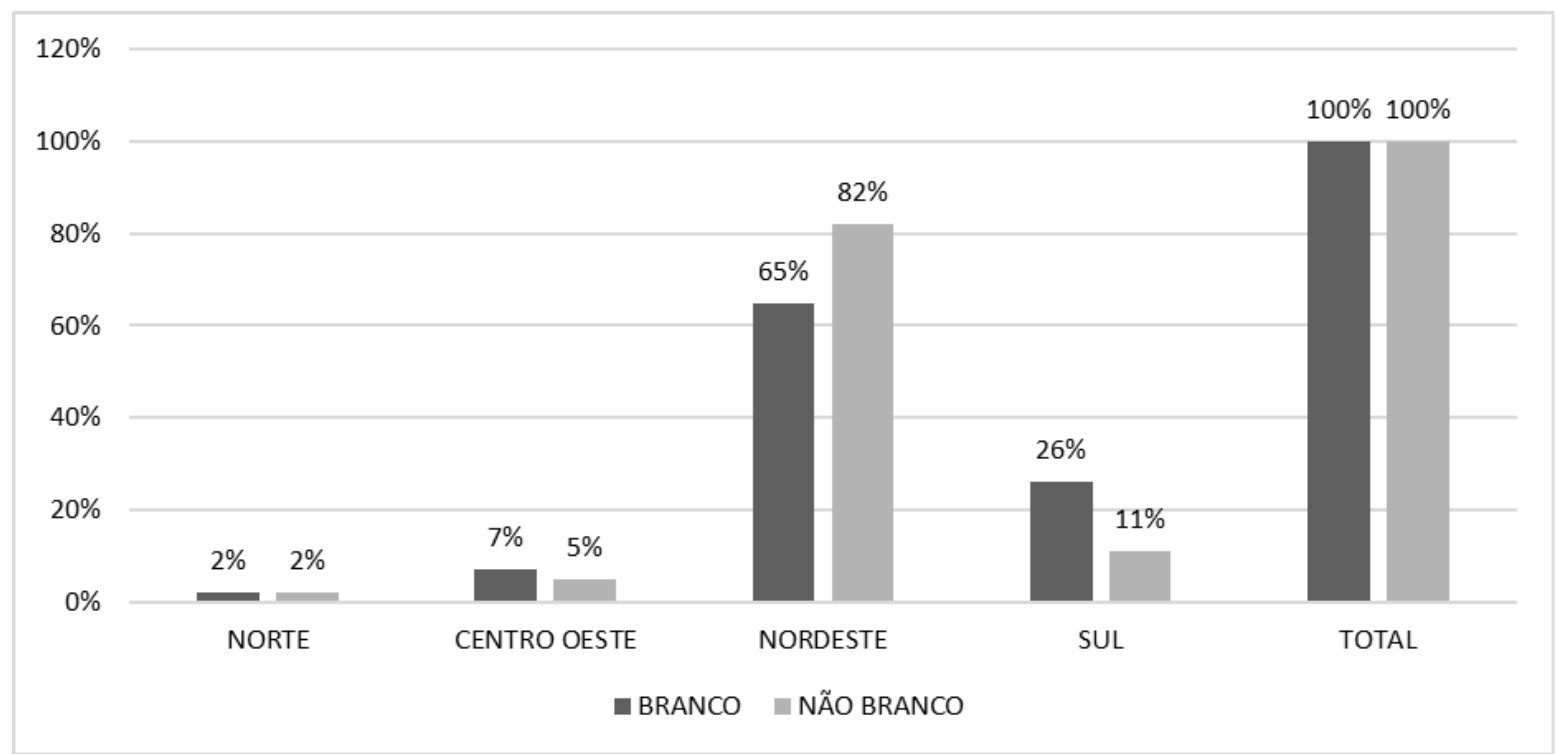

Fonte: Elaboração própria a partir da PNAD 2015.

Figura 2. Classificação dos migrantes por nível de escolaridade, 2015
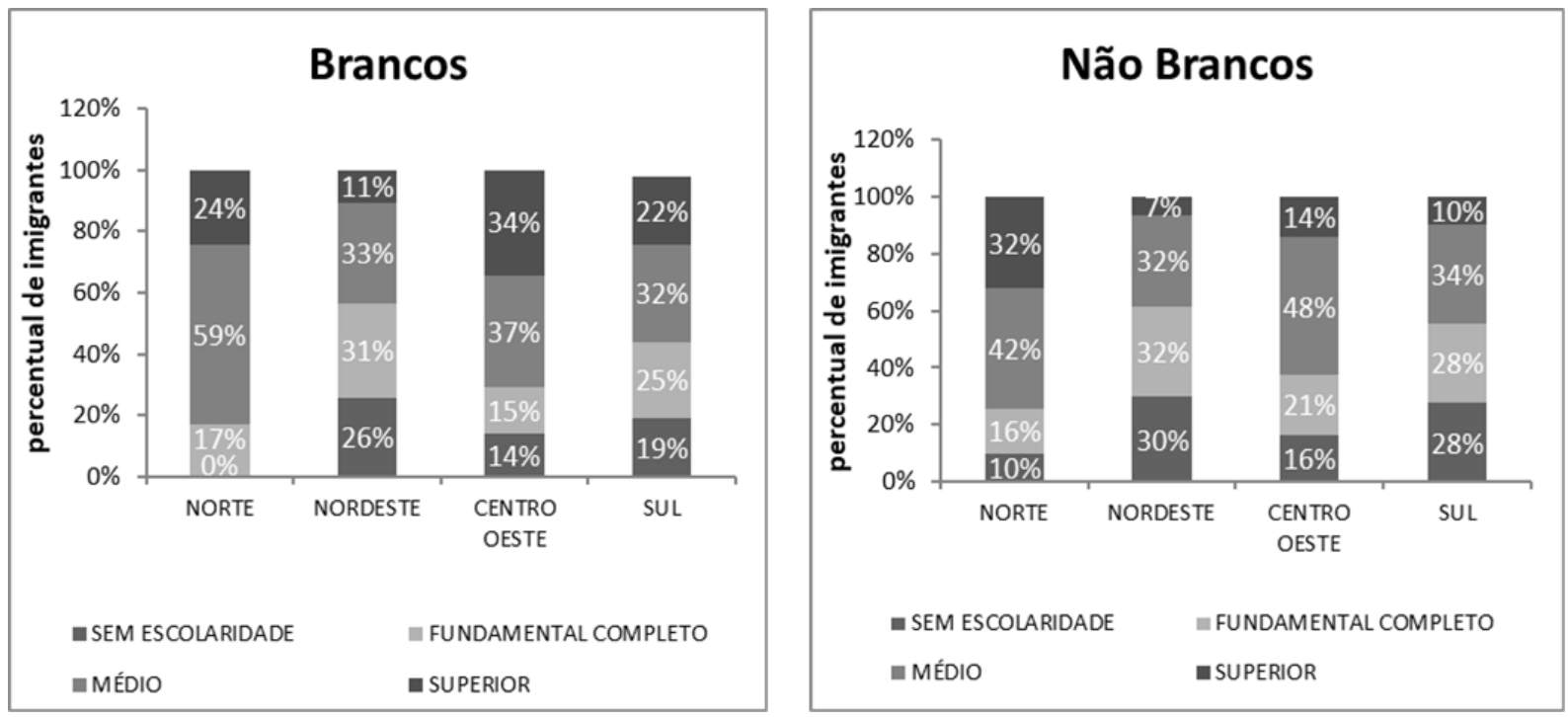

Fonte: Elaboração própria a partir da PNAD 2015.

Nesse aspecto, considerando a possibilidade de o migrante possuir viés de seletividade, como especificado na estratégia de identificação, ainda é importante analisar descritivamente as características dos indivíduos que nasceram e residiam na região Nordeste no período analisado, vide Tabela 3, abaixo.

A Tabela 3 revela que o percentual médio de trabalhadores formais que residem na região Nordeste (mantendo-se no local de nascimento) é relativamente inferior ao dos que migraram para o Sudeste. Contudo, em média, o percentual de indivíduos que possuem ensino superior (Esc4) é relativamente maior tanto para brancos quanto 
para não brancos. Em ambos os casos, o segmento de Comércio e Serviços é o que possui contingente mais elevado de indivíduos alocados. No entanto, verifica-se elevado percentual de trabalhadores atuantes no setor Agrícola, quando se compara com aqueles que migraram para a região Sudeste.

Tabela 3. Estatísticas descritivas dos indivíduos que nasceram e residem na região Nordeste

\begin{tabular}{lrrrrrr}
\hline \hline & \multicolumn{2}{c}{ Brancos } & & \multicolumn{2}{c}{ Não Brancos } \\
& (334 observações) & & (863 observações) \\
\cline { 2 - 3 } \cline { 6 - 7 } Característica & Média & $\begin{array}{r}\text { Desvio- } \\
\text { Padrão }\end{array}$ & & Média & $\begin{array}{r}\text { Desvio- } \\
\text { Padrão }\end{array}$ \\
\cline { 7 - 7 } Esc1 & $31 \%$ & 0,461 & & $38 \%$ & 0,4868 \\
Esc2 & $22 \%$ & 0,4138 & & $24 \%$ & 0,4243 \\
Esc3 & $29 \%$ & 0,456 & & $28 \%$ & 0,448 \\
Esc4 & $18 \%$ & 0,386 & & $10 \%$ & 0,302 \\
Agrícola & $18 \%$ & 0,384 & & $21 \%$ & 0,408 \\
Indústria & $10 \%$ & 0,306 & & $10 \%$ & 0,305 \\
Construção & $13 \%$ & 0,332 & & $20 \%$ & 0,4014 \\
Comércio e Serviço & $51 \%$ & 0,500 & & $40 \%$ & 0,4903 \\
Outros & $8 \%$ & 0,268 & & $8 \%$ & 0,273 \\
\hline \hline
\end{tabular}

Fonte: Elaboração própria a partir da PNAD 2015.

\subsection{Análise da equação de rendimentos}

Inicialmente, foi realizado o teste de Hausman, o qual denotou endogeneidade da variável que aponta a probabilidade de o indivíduo migrar (variável dependente da equação de seleção) com o rendimento na região de destino (variável dependente da equação de rendimentos), controlada pela utilização do instrumento correspondente ao logaritmo natural do número de migrantes, vide seção metodológica. Ademais, o teste de Wald mostrou que não há igualdade entre os coeficientes estimados para as equações de rendimentos e de seleção de Heckman. Por fim, o teste de Variance Inflation Factor (VIF) foi realizado, considerando as variáveis explicativas utilizadas na estimação dos dois estágios do Procedimento de Heckman, não indicando a existência de multicolinearidade.

Os resultados da estimação da equação de rendimentos são indicados na Tabela 4. De fato, é possivel notar que a escolaridade, especialmente referente ao nível superior, mostra-se positiva e estatisticamente significativa para determinação dos rendimentos em ambos os grupos. Em relação aos ramos de atividades, estimou-se relação negativa entre a atuação no setor Agrícola e a remuneração. Já a participação no ramo de 
Comércio e Serviços apenas foi estatisticamente significativa na amostra composta por caucasianos. Como esperado, a atuação em cargos de liderança, como direção ou gerência, é positivamente relacionada aos rendimentos.

Tabela 4. Equação de rendimentos estimada, considerando migrantes e não migrantes, ano 2015

\begin{tabular}{|c|c|c|c|c|}
\hline \multirow{3}{*}{ Variável } & \multicolumn{2}{|c|}{$\begin{array}{c}\text { Brancos } \\
\text { (6.058 observações) }\end{array}$} & \multicolumn{2}{|c|}{$\begin{array}{c}\text { Não Brancos } \\
\text { (9.184 observações) }\end{array}$} \\
\hline & Parâmetro & Desvio- & Parâmetro & \\
\hline & & Padrão & & Padrão \\
\hline Sind & 0,138 & $0,02^{* * *}$ & 0,130 & $0,02^{* * *}$ \\
\hline $\mathrm{Esc} 2$ & 0,229 & $0,03^{* * *}$ & 0,152 & $0,02 * * *$ \\
\hline Esc3 & 0,446 & $0,03^{* * *}$ & 0,286 & $0,02 * * *$ \\
\hline Esc4 & 1,114 & $0,04^{* * *}$ & 0,753 & $0,04^{* * *}$ \\
\hline Casado & 0,015 & 0,04 & 0,016 & 0,03 \\
\hline Agrícola & $-0,143$ & $0,05^{* * *}$ & $-0,246$ & $0,03^{* *}$ \\
\hline Indústria & $-0,010$ & 0,04 & 0,066 & 0,03 \\
\hline Construção & $-0,013$ & 0,04 & 0,023 & 0,03 \\
\hline Comércio e Serviços & $-0,084$ & $0,03^{* *}$ & $-0,039$ & 0,02 \\
\hline Urbano & 0,139 & $0,04^{* * *}$ & 0,136 & $0,03 * * *$ \\
\hline No_nasc & $-0,208$ & $0,04^{* * *}$ & $-0,157$ & $0,03^{* * *}$ \\
\hline Ne_nasc & $-0,150$ & $0,03^{* * *}$ & $-0,269$ & $0,02^{* * *}$ \\
\hline Su_nasc & 0,061 & $0,03^{* *}$ & $-0,093$ & $0,03^{* *}$ \\
\hline Exper & 0,039 & $0,00^{* * *}$ & 0,033 & $0,00^{* * *}$ \\
\hline Exper2 & $-0,001$ & $0,00^{* * *}$ & 0,000 & $0,00^{* * *}$ \\
\hline Diretor & 0,533 & $0,04^{* * *}$ & 0,647 & $0,04 * * *$ \\
\hline Mills & $-0,051$ & $0,01^{* * *}$ & $-0,096$ & $0,01^{* * *}$ \\
\hline _cons & 6,503 & $0,09 * * *$ & 6,764 & $0,05^{* * *}$ \\
\hline
\end{tabular}

Nota: Indicam *** 1\%; ** 5\%; * 10\% de significância.

Fonte: Elaboração própria a partir da PNAD 2015.

No presente estudo, o resultado da razão inversa de Mills indica que os migrantes com destino ao Sudeste são negativamente selecionados no mercado de trabalho, ou seja, esses possuem características que em média corroboram um rendimento inferior.

É interessante ressaltar que a região de nascimento do migrante mostra-se estatisticamente significante em relação aos rendimentos. Dado que estes são expressos em 
termos logarítmicos, o rendimento do nordestino é $15 \%$ e $27 \%$ inferior, se comparado, respectivamente, ao dos trabalhadores brancos e não brancos do Centro-Oeste.

Os caucasianos nascidos no Sul possuem 6\% de vantagem salarial, mas os não brancos nascidos no Sul recebem cerca de 9\% a menos que seus semelhantes oriundos do Centro-Oeste. Destaca-se que, de acordo com as estatísticas descritivas, os indivíduos caucasianos, que migraram para o Sudeste, são preponderantemente nordestinos e sulistas. Em relação aos migrantes não caucasianos, a maioria é proveniente das regiões Nordeste e Norte, os quais estão negativamente relacionados com os rendimentos, quando comparados aos da região Centro-Oeste.

O resultado da razão inversa de Mills retrata que os indivíduos não brancos, que migraram para o Sudeste, são negativamente selecionados. Todavia, a constatação de que a região de nascimento impacta os rendimentos não é suficiente para verificar se o mercado de trabalho do Sudeste diferencia o migrante em decorrência disso. Essa questão é analisada através da decomposição de Oaxaca-Blinder, pela qual se pode inferir que o grau de diferenciação salarial se distingue tanto pela cor quanto pela região de origem do migrante.

Os resultados da decomposição também permitirão verificar se o migrante nordestino está sujeito ao comportamento discriminatório e se as características explicadas da diferenciação salarial existente entre os migrantes de diversas origens são decorrentes de fatores similares. Essas considerações são apresentadas nas três subseções seguintes, nas quais se explanam as estimações da decomposição de Oaxaca-Blinder entre os pares de migrantes residentes na região Sudeste.

\subsection{Comparação entre migrantes das regiões Nordeste e Norte}

Nesta subseção, discute-se a primeira comparação entre os rendimentos recebidos dos indivíduos nascidos nas regiões Norte e Nordeste do país, que se deslocaram para a região Sudeste. A Tabela 5 indica os resultados dessa análise. Nota-se que não há diferença salarial estatisticamente significante entre migrantes brancos nascidos nas regiões Nordeste e Norte, sendo que o mesmo não ocorre para os migrantes não brancos. No presente estudo, verifica-se que há diferenciação salarial motivada tanto por características explicadas quanto não explicadas, desfavoráveis ao nordestino não branco.

Dentre os fatores que explicam a diferença salarial, destaca-se a escolaridade no ensino superior, a qual se apresentou como um parâmetro positivo e significativo na decomposição. Paralelamente, o nível de escolaridade equivalente ao ensino fundamental mostrou-se negativamente correlacionado aos rendimentos.

Quando se compara a escolaridade média dos indivíduos não brancos, percebese que apenas $6 \%$ dos nordestinos possuem ensino superior completo, enquanto que cerca de 30\% não finalizaram o ensino fundamental. A Figura 1, já apresentada, 
demonstrou que tal proporção é praticamente inversa para os indivíduos nascidos na região Norte. Conforme exposto na estimação da equação de rendimentos, esse pode ser um determinante para o diferencial existente. Assim, o componente inexplicado pode ser interpretado como a diferença decorrente da discriminação.

Tabela 5. Decomposição Oaxaca-Blinder: imigrantes das regiões Nordeste e Norte, 2015

\begin{tabular}{lrrrrr}
\hline \hline \multirow{2}{*}{ Diferença } & \multicolumn{2}{c}{ Brancos } & & \multicolumn{2}{c}{ Não Brancos } \\
\cline { 2 - 3 } \cline { 5 - 6 } \cline { 5 - 6 } & Parâmetro & Desvio-Padrão & & Parâmetro & Desvio-Padrão \\
\hline Explicada & 0,157 & 0,24 & & 0,713 & $0,21^{* * *}$ \\
Inexplicada & 0,151 & $0,09^{*}$ & & 0,080 & $0,05^{*}$ \\
\hline \hline
\end{tabular}

Nota: Indicam *** 1\%; ** 5\%; * 10\% de significância.

Fonte: Elaboração própria a partir da PNAD 2015, SIS 2010 e Ribeiro (2017).

\subsection{Comparação entre os migrantes das regiões Nordeste e Sul}

A segunda comparação foi realizada entre os migrantes oriundos das regiões Nordeste e Sul, residentes na região Sudeste. Similarmente ao que fora apresentado na subseção anterior, objetiva-se verificar se os trabalhadores nordestinos são discriminados no mercado de trabalho, porém comparando-os com os sulistas.

A diferença salarial total entre os migrantes nordestinos e os sulistas foi estatisticamente significativa para o grupo composto por homens brancos, mas não o foi para os não brancos e a Tabela 6 retrata esse resultado.

Tabela 6. Decomposição Oaxaca-Blinder: imigrantes das regiões Nordeste e Sul, 2015

\begin{tabular}{lrrrrr}
\hline \hline \multirow{2}{*}{ Diferença } & \multicolumn{2}{c}{ Brancos } & & \multicolumn{2}{c}{ Não Brancos } \\
\cline { 2 - 3 } \cline { 5 - 6 } \cline { 5 - 6 } & Parâmetro & Desvio-Padrão & & Parâmetro & Desvio-Padrão \\
\hline Explicada & 0,234 & $0,122^{*}$ & & 0,181 & 0,134 \\
Inexplicada & 0,151 & $0,03^{* * *}$ & & 0,051 & $0,02^{* *}$ \\
\hline \hline
\end{tabular}

Nota: Indicam *** 1\%; ** 5\%; * 10\% de significância.

Fonte: Elaboração própria a partir da PNAD 2015, SIS 2010 e Ribeiro (2017).

Pode-se concluir que os migrantes sulistas caucasianos também tendem a apresentar rendimentos superiores aos dos nordestinos em função do acesso ao ensino superior. Na média, observa-se que o percentual de sulistas caucasianos com ensino superior supera em dobro o dos nordestinos. O cargo ocupado também se mostrou 
relevante para justificar a diferença salarial. A partir da amostra observada, 5\% dos migrantes nordestinos trabalhavam em cargos de liderança no Sudeste, enquanto os sulistas ocupavam $10 \%$ das posições.

\subsection{Comparação entre os migrantes das regiões Nordeste e Centro-Oeste}

Por fim, a terceira análise foi realizada com o intuito de comparar os rendimentos dos migrantes nascidos na região Nordeste com daqueles nascidos na região CentroOeste, vide Tabela 7, que apresenta a decomposição de Oaxaca-Blinder. Para os caucasianos, a diferença entre os rendimentos foi estatisticamente significativa e justificada, como aponta a estatística do componente explicado. Nessa amostra, a diferença total entre os não brancos não se mostrou significativa.

Tabela 7. Decomposição Oaxaca-Blinder: imigrantes regiões Nordeste e CentroOeste, 2015

\begin{tabular}{lrrrrr}
\hline \hline \multirow{2}{*}{ Diferença } & \multicolumn{2}{c}{ Brancos } & & \multicolumn{2}{c}{ Não Brancos } \\
\cline { 2 - 3 } \cline { 5 - 6 } \cline { 5 - 6 } & Parâmetro & Desvio-Padrão & & Parâmetro & Desvio-Padrão \\
\hline Explicada & 0,312 & $0,151^{* *}$ & & $-0,124$ & 0,175 \\
Inexplicada & 0,233 & $0,059^{* * *}$ & & 0,041 & 0,038 \\
\hline \hline
\end{tabular}

Nota: Indicam *** 1\%; ** 5\%; * 10\% de significância.

Fonte: Elaboração própria a partir da PNAD 2015, SIS 2010 e Ribeiro (2017).

A principal justificativa para a diferença salarial explicada do indivíduo branco é a escolaridade de nível superior. Similarmente aos resultados anteriores, a posição de liderança no trabalho, em que $14 \%$ dos migrantes nascidos na região Centro-Oeste ocupavam tais cargos, também é um fator que explica o diferencial. Ademais, a quantidade de migrantes nordestinos que possuem apenas o ensino fundamental é em média o dobro da referente ao grupo comparado, o que influencia negativamente o diferencial de rendimentos.

Para os três casos, é possivel apontar algumas similaridades importantes para responder ao questionamento central do presente estudo. A discussão geral a respeito da discriminação dos migrantes nordestinos no mercado de trabalho da região Sudeste é apresentada na subseção seguinte.

\subsection{Discussões gerais a respeito dos resultados}

No geral, os resultados apontam que o trabalhador nordestino, que migra para a região Sudeste, é negativamente selecionado, de modo que seu retorno salarial em decorrência da migração tende a ser inferior se comparado ao dos migrantes nascidos 
nas demais regiões do país. Contudo, quase sempre esse diferencial não é decorrente de efeitos discriminatórios, sendo majoritariamente explicado pela diferença no nível de escolaridade. A exceção encontra-se no grupo de trabalhadores não brancos, quando comparados àqueles nascidos na região Norte do país, onde é possivel verificar uma discrepância salarial não explicada, desfavorável ao nordestino.

Esse resultado complementa as conclusões levantadas por Loureiro (2003); Maciel e Cunha (2013), os quais afirmam que o migrante nordestino é negativamente selecionado. O nível de escolaridade, especialmente referente ao ensino superior, foi o principal fator explicativo para as diferenças salariais entre os grupos de migrantes. A partir do Gráfico 2, foi possível evidenciar que os nordestinos estão em desvantagem nesse aspecto. Nesse sentido, a relevância da educação superior também foi evidenciada por Moura (2008).

As demais variáveis inseridas como controles do modelo também apresentaram resultados condizentes com estudos anteriores. A relação positiva entre a filiação sindical e o rendimento condiz com o trabalho de Sachsida et al. (2004). Quanto ao setor de atividades, a atuação no setor agrícola pode acarretar relação negativa com o rendimento, devido ao fato de esse ser majoritariamente composto por mão de obra não especializada e localizada em zonas não urbanas. Por sua vez, a incidência de maiores retornos salariais decorrentes das melhores condições de trabalho presentes nas zonas urbanas é indicada por Santos (2006).

A relação negativa, expressa pelo parâmetro ligado ao comércio, também é encontrada por Maciel e Cunha (2013), mas diferente das autoras, a estimação do modelo para brancos e não brancos permite verificar que o efeito dos ramos de atividade é estatisticamente distinto entre tais grupos. Nesse caso, para os migrantes não brancos, a atuação no segmento comercial ou de serviços não foi estatisticamente significativa.

\section{Considerações finais}

O presente estudo se baseou na teoria econômica da discriminação para verificar se a região de origem do migrante interno brasileiro determina diferenciação salarial. Diante dos longos períodos de emigração da região Nordeste e do histórico e persistente atraso socioeconômico da região comparada às demais, optou-se por especificar a análise em relação ao migrante nordestino com destino à região Sudeste, que ainda permanece como o principal local de destino dos migrantes internos.

Verificou-se que os rendimentos dos migrantes nordestinos são de fato inferiores se comparados aos dos demais migrantes. Entretanto, constata-se que apenas o indivíduo não branco, comparado com aqueles oriundos da região Norte, está sujeito ao efeito discriminatório relacionado ao local de nascimento.

Apesar de a análise empírica corroborar a teoria econômica da discriminação estatística para o caso supracitado, essa não permite distinguir o tipo de discriminação 
sofrida - se é exclusivamente salarial, de emprego, de trabalho ou de oportunidades. Para tal, seria necessária uma estratégia de identificação distinta, a qual poderá ser desenvolvida em estudos futuros. Quanto às diferenças salariais encontradas nas demais regiões, essas são explicadas pelas disparidades no percentual de migrantes com ensino superior.

\section{Referências}

Aguiar, M. A. S., de Sousa, D. T., e Rodrigues, P. S. (2018). Diferenciais de salários na região Nordeste: uma análise segundo condição de migração e nível educacional. Revista Brasileira de Estudos Regionais e Urbanos, 12(4):436-452.

Angrist, J. D. e Pischke, J.-S. (2008). Mostly harmless econometrics: An empiricist's companion. Princeton University Press.

Arcand, J.-L. e D'hombres, B. (2004). Racial discrimination in the Brazilian labour market: Wage, employment and segregation effects. Journal of International Development: The Journal of the Development Studies Association, 16(8):1053-1066.

Arrow, K. (1973). The theory of discrimination, discrimination in labor markets. In: Discrimination in labor markets. Princeton-New Jersey.

Baeninger, R. (2012). Rotatividade migratória: um novo olhar para as migrações internas no Brasil. Revista Interdisciplinar da Mobilidade Humana, 39:77-100.

Barbosa Filho, F. H. e Abreu Pessôa, S. (2010). Educação e crescimento: o que a evidência empírica e teórica mostra? Revista Economia, 11(2):265-303.

Batista, N. N. F. e Cacciamali, M. C. (2009). Diferencial de salários entre homens e mulheres segundo a condição de migração. Revista Brasileira de Estudos de População, 26(1):97-115.

Becker, G. S. (1957). The economics of discrimination. University of Chicago Press.

Becker, G. S. (1993). Human capital: A theoretical and empirical analysis, with special reference to education. University of Chicago Press.

Beller, A., Borjas, G., Tienda, M., Bloom, D., e Grenier, G. (1994). Beauty and the labor market. The American Economic Review, 84(5):1174-1194.

Blinder, A. S. (1973). Wage discrimination: reduced form and structural estimates. Journal of Human Resources, (4):436-455.

Bóo, F. L. e Trako, I. (2009). Labor market discrimination based on gender and socioeconomic level of the place of residence: A randomized experiment in Argentina. Social Science Research Network, 4:12-54.

Borjas, G. J. (1994). The economics of immigration. Journal of Economic Literature, 32(4):1667-1717. 
Branchi, B. e Barretto, V. V. (2010). Mercado de trabalho, desigualdade de renda e migração: o caso da Região Metropolitana de Campinas. Perspectiva Econômica, 6(1):63-90.

Cambota, J. N. e Marinho, E. L. L. (2007). Discriminação como uma das fontes de desigualdade de rendimentos no mercado de trabalho das regiões Nordeste e Sudeste. Revista EconomiA, 7(1):597-619.

Cameron, A. C. e Trivedi, P. K. (2005). Microeconometrics: methods and applications. Cambridge University Press.

Campante, F. R., Crespo, A. R. V., e Leite, P. G. P. G. (2004). Desigualdade salarial entre raças no mercado de trabalho urbano brasileiro: aspectos regionais. Revista Brasileira de Economia, 58(2):185-210.

Cano, W. (1997). Concentração e desconcentração econômica regional do Brasil 1970/95. Economia e Sociedade, 6(1):101-141.

Carvalho, A. P., Neri, M. C., e Silva, D. B. (2006). Diferenciais de salários por raça e gênero: aplicação dos procedimentos de Oaxaca e Heckman em pesquisas amostrais complexas. Ensaios Econômicos, 638:9-34.

Cunha, J. M. P. (2005). Migração e urbanização no Brasil: alguns desafios metodológicos para análise. São Paulo em Perspectiva, 19(4):3-20.

Darity, W. A. (1998). Intergroup disparity: Economic theory and social science evidence. Southern Economic Journal, 64(4):806-826.

Fawcett, J. T. (1989). Networks, linkages, and migration systems. International Migration Review, 23(3):671-680.

Fazito, D. (2002). A análise de redes sociais (ARS) e a migração: mito e realidade. Encontro da ABEP.

Fernandes, G. A. d. A. L. (2015). Brazilian female labor market: racial-skin color discrimination and inefficiency. Economia Aplicada, 19(2):241-259.

Gama, L. C. D. e Machado, A. F. (2014). Migração e rendimentos no Brasil: análise dos fatores associados no período intercensitário 2000-2010. Estudos Avançados, 28(81):155-174.

Heckman, J. J. (1979). Sample selection bias as a specification error. Econometrica: Journal of the Econometric Society, 25(1):153-161.

Jann, B. (2008). A Stata implementation of the Blinder-Oaxaca decomposition. Stata Journal, 8(4):453-479.

Loureiro, P. R. A. (2003). Uma resenha teórica e empírica sobre economia da discriminação. Revista Brasileira de Economia, 57(1):125-157. 
Maciel, F. T. e Cunha, M. S. (2013). Migração e diferenciais de rendimento no Brasil: uma análise sobre o efeito do tempo de chegada ao local de destino. Revista Econômica do Nordeste, 44(3):627-650.

Martine, G. (1980). Adaptação dos migrantes ou sobrevivência dos mais fortes? In: Migração interna: textos selecionados. Fortaleza: Banco do Nordeste do Brasil.

Massey, D. S., Arango, J., Hugo, G., Kouaouci, A., Pellegrino, A., e Taylor, J. E. (1993). Theories of international migration: A review and appraisal. Population and Development Review, 19(4):431-466.

Mincer, J. (1958). Investment in human capital and personal income distribution. Journal of Political Economy, 66(4):281-302.

Moura, R. L. d. (2008). Testando as hipóteses do modelo de Mincer para o Brasil. Revista Brasileira de Economia, 62(4):407-449.

Oaxaca, R. (1973). Male-female wage differentials in urban labor markets. International Economic Review, 54:693-709.

Phelps, E. S. (1972). The statistical theory of racism and sexism. The American Economic Review, 62(4):659-661.

Ribeiro, A. C. (2017). Ensaios em economia da migração: uma análise de padrões migratórios no Brasil. Tese (Doutorado em Economia do Desenvolvimento) - Escola de Negócios, Pontifícia Universidade Católica do Rio Grande do Sul.

Rodrigues, K. C. T. T., de Souza, S. C. I., Moura, F. K. F., e Maia, K. (2016). Diferencial salarial segundo a condição de migração e gênero nos estados da região sul do Brasil. Economia \& Região, 4(1):7-23.

Sachsida, A., Loureiro, P. R. A., e Mendonça, M. J. C. (2004). Um estudo sobre retorno em escolaridade no Brasil. Revista Brasileira de Economia, 58(2):249-265.

Sahota, G. S. (1968). An economic analysis of internal migration in Brazil. Journal of Political Economy, 76(2):218-245.

Santos, C. (2006). Migração e distribuição regional de renda no Brasil, 2006. Dissertação (Escola de Pós-Graduação em Economia - EPGE), Fundação Getúlio Vargas.

Souza, S. d. C. I., Maia, K., Fiuza-Moura, F. K., Gomes, M. R., e da Silva, R. J. (2015). Diferenças salariais por gênero e cor e o impacto da discriminação econômica. $R e-$ vista Brasileira de Estudos Regionais e Urbanos, 9(1):32-49.

Veit, S. e Thijsen, L. (2019). Almost identical but still treated differently: hiring discrimination against foreign-born and domestic-born minorities. Journal of Ethnic and Migration Studies, 42:1-20.

Yap, L. (1976). Internal migration and economic development in Brazil. The Quarterly Journal of Economics, 90(1):119-137. 
Yinger, J. (1998). Evidence on discrimination in consumer markets. Journal of Economic Perspectives, 12(2):23-40.

(G) Este artigo está licenciado com uma CC BY 4.0 license. 